\title{
Methods for Screening Wheat Genotypes for Resistance to Sharp Eyespot in the Field and Greenhouse
}

\author{
Jiang Liu, ${ }^{1}$ Nicole P. Anderson, ${ }^{2}$ and Christopher C. Mundt ${ }^{1, \dagger}$ \\ ${ }^{1}$ Department of Botany and Plant Pathology, Oregon State University, Corvallis, OR 97331-2902, U.S.A. \\ ${ }^{2}$ Department of Crop and Soil Science, Oregon State University, Corvallis, OR 97331-2821, U.S.A.
}

\begin{abstract}
Screening methodology of wheat genotypes for resistance to sharp eyespot (caused by Rhizoctonia cerealis) was developed. Disease severity differed among cultivars and between field and greenhouse trials. However, the cultivars Bobtail and Rosalyn had consistently lower severity in field experiments with high sharp eyespot disease pressure. Artificial in-

of adult wheat plants was much less successful in categorizing resistance to sharp eyespot. Seedling inoculations in the greenhouse were highly inadequate as a screening method. Selection for resistance to sharp eyespot by artificial inoculation in field trials is feasible in wheat breeding programs.
\end{abstract} oculation was crucial to achieving adequate disease levels for effective screening but planting date had very little effect. Greenhouse inoculation
Keywords: Rhizoctonia cerealis, sharp eyespot, wheat.
Wheat sharp eyespot caused by the soilborne basidiomycete fungus Rhizoctonia cerealis E. P. Hoeven (teleomorph: Ceratobasidium cereale D. I. Murray \& Burpee) is one of the most common diseases found in wheat (Triticum aestivum L.) crops globally. It has been reported in many area of the world, including the United States (Bockus et al. 2010), China (Li et al. 2017), New Zealand (Cromey et al. 2005), South America (Hamada et al. 2011), the United Kingdom (Lovell et al. 2003), Egypt (Hammouda 2003), and Poland (Lemańczyk 2010).

The severity of sharp eyespot has increased substantially throughout the world in recent decades for reasons that are not yet clear, and poses a significant threat to global wheat production (Hamada et al. 2011). Moderate to severe sharp eyespot causes yield losses of 5 to $26 \%$ in the United Kingdom (Clarkson and Cook 1983). In New Zealand, the disease can cause at least $32 \%$ reduction of tillers, $47 \%$ loss of kernel weight, and $48 \%$ loss of kernel number (Cromey et al. 2002). In China, sharp eyespot is prevalent in more than 10 provinces, including the main wheat production areas, where it causes 5 to $10 \%$ yield loss in less severely infected fields and 20 to $40 \%$ loss in severely infected fields (Chen et al. 2011). The yield losses caused by sharp eyespot in Egypt are reported to be around 20 to 30\% (Hammouda 2003).

If available, the planting of resistant cultivars would be a desirable approach for managing sharp eyespot, because it is an economically and environmentally friendly approach. Unfortunately, no wheat cultivar has been found to possess a consistently high level of resistance to this disease. In New Zealand, some wheat cultivars were found to be more resistant to sharp eyespot than others but the ranking of their resistance was not consistent across locations or years (Cromey et al. 2005). The primary infection process was similar between

${ }^{\dagger}$ Corresponding author: C. C. Mundt; mundtc@ science.oregonstate.edu

Funding: This work was supported by the Oregon Wheat Commission, royalty funds through the Oregon State University Wheat Breeding and Genetics Program, and the Oregon State University Agricultural Experiment Station.

*The $\boldsymbol{e}$-Xtra logo stands for "electronic extra" and indicates that supplementary figures and supplementary tables are published online.

The author(s) declare no conflict of interest.

Accepted for publication 8 June 2020 .

(C) 2020 The American Phytopathological Society susceptible and moderately resistance cultivars. However, lesion spread from the outer to inner infected leaves and stems was reduced on the resistant cultivars (Cromey et al. 2012). According to Cromey et al. (2005, 2012), the cultivars Regency and Centaur had high resistance to sharp eyespot in some field trials and greenhouse experiments but not others. Most cultivars tested in their trials expressed intermediate to high susceptibility to the disease. Lovell et al. (2003) reported that sharp eyespot severity on dwarf wheat nearisogenic lines with a height of 35 to $50 \mathrm{~cm}$ was much greater than that on the taller recurrent parent lacking the dwarfing genes. Li et al. (2013) indicated that only 34 of 321 tested wheat cultivars showed low to moderate resistance to sharp eyespot in the fields of Xuzhou, China but none of them showed resistance in Nanjing.

In North America, sharp eyespot in wheat crops has attracted relatively little attention in the past due to minimal economic loss, despite the fungus being widely present (Lipps and Herr 1982). However, this situation has changed since 2014 when the disease was severe throughout the Willamette Valley of Oregon, with yield losses of up to $50 \%$ in some fields. Sharp eyespot has remained an important disease in the Willamette Valley subsequently (unpublished data). Based on population genetic analyses, this change in importance of sharp eyespot in the Willamette Valley might be associated with the occurrence of the sexual stage, which would allow widespread dispersal via basidiospores (Liu and Mundt 2020). Thus, there is a strong need to develop resistant cultivars in this region. The aim of this research was to develop screening methods for sharp eyespot in both field and greenhouse trials and to determine whether results from field and greenhouse trials provide similar ranking of wheat genotypes for resistance to this disease.

\section{Materials and Methods}

Wheat cultivars. Six soft white winter wheat cultivars were chosen for this study to provide a range from the most resistant to the most susceptible. These disease reactions came from a preliminary evaluation (see below) of cultivars and breeding lines observed in winter wheat variety trials in 2014 and 2015. Five of the cultivars were recently commercially grown in the Willamette Valley and have excellent yield performance in the region. The sixth cultivar, Ladd, is less competitive in yield in the Willamette Valley but was chosen for its intermediate reaction to sharp eyespot. Four of the six cultivars (Bobtail, Kaseberg, Rosalyn, and Ladd) were released by Oregon State University. The other two (LCS Art Deco and LCS Biancor) are popular cultivars released by Limagrain Cereal Seeds LLC.

Preliminary field evaluations in growers' fields. While surveying the 2014 outbreak on 23 June, we observed considerable 
differences in disease levels among entries in the Oregon State University Soft White Winter Elite Yield Trial in Forest Grove, OR $\left(45^{\circ} 31^{\prime} 10.19^{\prime \prime} \mathrm{N}, 123^{\circ} 06^{\prime} 19.20^{\prime \prime} \mathrm{W}\right)$ in the northern part of the Willamette Valley. This trial consisted of 40 entries, including the six wheat cultivars described above, with four replications in a randomized complete block design using standard 1.52-by-6.1-m yield trial plots. The trial was planted in a commercial wheat field using standard agronomic practices, including application of Quilt Xcel (Syngenta; active ingredients [a.i.] = azoxystrobin + propiconazole) on 1.02 liter/ha 1 May and Prosaro (Bayer, a.i. = prothioconazole + tebuconazole) at 0.475 liter/ha on 20 May to control foliar disease. The disease severity was based on the observation of an entire plot. Each plot was rated on a 0-to-5 scale that was developed in the field based on a combination of whitehead expression of entire plot (early maturity of seed heads due to the presence of disease) and stem discoloration, where $0=$ no disease and $5=$ severe disease. The same method was applied to the 2015 variety trial on 19 June, also in Forest Grove, OR. This trial utilized the same design and plot size as in 2014 but in a different commercial field and with fungicide control of foliar diseases through application of Quilt Xcel at 1.02 liter/ha on 16 April. All six of our cultivars of interest were again included in the trial.

Preparation of inoculum. A mixture of four $R$. cerealis isolates isolated previously was used in the artificially inoculated trials. Two were isolated from breeding plots in Corvallis, OR $\left(44^{\circ} 33^{\prime}\right.$ $52.44^{\prime \prime} \mathrm{N}, 123^{\circ} 15^{\prime} 43.37^{\prime \prime} \mathrm{W}$ ) and the other two were isolated from a commercial winter wheat field (cultivar LCS Biancor) near Junction City, OR (44 $\left.13^{\prime} 9.44^{\prime \prime} \mathrm{N}, 123^{\circ} 12^{\prime} 20.34^{\prime \prime} \mathrm{W}\right)$ in 2017 . Wheat samples with typical sharp eyespot lesions were collected and cultured on water agar plates at $25^{\circ} \mathrm{C}$ in the dark for 2 to 5 days. Hyphal tips of the colonies were then transferred to potato dextrose agar (PDA) plates and cultured at $25^{\circ} \mathrm{C}$ in the dark for 2 to 5 days (Liu and Mundt 2020). The pure cultures, which had been stored at $-80^{\circ} \mathrm{C}$, were activated in Petri plates containing PDA and incubated in the dark at $20^{\circ} \mathrm{C}$ for 5 to 7 days. The colonized PDA media were then cut into $5-\mathrm{mm}^{2}$ pieces, once they were fully covered with mycelium of $R$. cerealis. Each piece was placed onto a new PDA plate to regenerate the fungus. The new plate was cultured in a dark incubator at $20^{\circ} \mathrm{C}$ for another 5 days.

Clean wheat seed were soaked in tap water for 24 to $48 \mathrm{~h}$ to increase their water content. The seed were then placed into spawn bags (Midwest Grow Kits, Algonquin, IL, U.S.A.), 454 g per spawn bag, and autoclaved twice (90 min each time) on successive days. The spawn bags were placed unsealed in a laminar flow hood for $10 \mathrm{~min}$ to allow excess moisture to evaporate.

The PDA media fully covered by $R$. cerealis mycelium were cut into $5-\mathrm{mm}^{2}$ pieces and put into spawn bags with autoclaved seed, about two to three plates per bag. The seed and fungus were mixed evenly. The bags were then sealed and placed in the incubator at $20^{\circ} \mathrm{C}$ for 2 to 3 weeks. Once the seed were covered with $R$. cerealis mycelium, they were spread out in a single layer on a lab workbench covered in butcher paper and dried for about $48 \mathrm{~h}$.

Artificially inoculated field experiments, 2017-18. A split-plot design with six wheat cultivars, four inoculation levels $(0,112$, 224, and $336 \mathrm{~kg} / \mathrm{ha}$ ), and four blocks was used at the Oregon State University Botany and Plant Pathology Field Laboratory (Botany Farm) and Oregon State University Hyslop Crop Science Field Research Laboratory (Hyslop Farm) (Supplementary Fig. S1). The inoculum levels were determined based on a previous report, in which $400 \mathrm{~kg} / \mathrm{ha}$ was applied (Chen 2014). There were main plots and subplots within each block (the areas between thick borders in Supplementary Fig. S1). The Botany Farm experiment was planted on 28 September 2017 in 3.05-by-0.762-m subplots, with two rows in each subplot. At the Hyslop Farm, the experiment was planted on 17 October 2017, also in 3.05-by-0.762-m subplots but with three rows in each subplot. Each experiment consisted of four replicate blocks. Each block consisted of four main plots, to which inoculum treatments were applied. Each main plot was divided into six subplots, each planted with a different cultivar. Main plots were separated from one another laterally by 0.762 -m-wide buffer plots of cultivar Jacmar as buffers.
Inoculations were completed on 2 February 2018 at both locations. The wheat plants at Hyslop Farm and Botany Farm were in the green-up stage (Feekes 4-5) (Large 1954) and jointing stage (Feekes 6), respectively. Each main plot was divided into 12 small areas, each 3.05 by $0.762 \mathrm{~m}$ (marked with flags or wooden stakes the day before). The inoculum for each small area was put into one coin envelope: $0 \mathrm{~g}$ ( $26 \mathrm{~g}$ of clean autoclaved and dried wheat seed) and 13, 26, and $39 \mathrm{~g}$ of inoculum. The inoculum in each envelope was evenly distributed over the rows in each small area by hand.

Artificially inoculated field experiments, 2018-19. Experiments consisting of a split-plot design with six wheat cultivars, two inoculation levels ( 0 and $336 \mathrm{~kg} / \mathrm{ha}$ ), and four blocks were conducted at the Botany Farm and Hyslop Farm. At each farm, seed were planted on two different dates (Supplementary Fig. S2). The early-planted experiments were sown on 17 and 18 September 2018 at the Botany Farm and Hyslop Farm, respectively. The late-planting experiments were identical to the early experiments and seeded on 15 October 2018 at both locations. The two planting dates at each location were planted adjacent to each other, because the logistics of tillage and planting equipment precluded the use of a split-plot design that included planting date. Both locations and planting dates used 3.05-by-0.762-m subplots, with two rows in each subplot. Each experiment consisted of four replicate blocks. Each block consisted of two main plots to which inoculation treatments were applied. Each main plot was divided into six subplots, each planted with a different cultivar. Main plots were separated from one another laterally by 0.762-m-wide buffer plots of cultivar Bobtail.

The inoculations of both early- and late-planting experiments were completed on 3 January and 18 February 2019 at both farms, when the plants were in Feekes 4-5 (Large 1954). The inoculation method was same as in the previous year.

Greenhouse experiments, 2017-18. Two separate trials were carried out to evaluate the resistance of cultivars at both the adult and seedling stages. In the first experiment, in which adult stage resistance was tested, a completely randomized design (CRD) with three treatments (cultivar, inoculation level, and soil covering of inoculum) and five replications was used. The same six wheat cultivars were used as in the field experiments. The inoculation levels were 0 (6 clean autoclaved and dried wheat seeds) and 2, 4, 6, 8, and 10 seeds infested with $R$. cerealis mycelium and placed next to each plant. Infested wheat kernels were produced as described above for the field experiments. The two soil-covering treatments were either inoculum covered with about $1 \mathrm{~cm}$ of soil or no covering of inoculum.

The six wheat cultivars were germinated and grown in a greenhouse for 12 to 14 days and then placed in a vernalization chamber with a photoperiod of $8 \mathrm{~h}$ of light and $16 \mathrm{~h}$ of darkness per day and day and night temperature of $8^{\circ} \mathrm{C}$ for 7 weeks. All plant materials were then transplanted into plastic cones ( 4 by $21 \mathrm{~cm}$ ) after vernalization and moved back into the greenhouse with a photoperiod of $16 \mathrm{~h}$ of light and $8 \mathrm{~h}$ of darkness per day and day and night temperatures of 23 and $18^{\circ} \mathrm{C}$, respectively. The inoculum was applied 7 days after moving the plants back to the greenhouse.

In the seedling assessment experiment, the six wheat cultivars were germinated and grown in cones in the greenhouse for 12 to 14 days with a photoperiod of $16 \mathrm{~h}$ of light and $8 \mathrm{~h}$ of darkness per day and day and night temperatures of 23 and $18^{\circ} \mathrm{C}$, respectively. The inoculum was applied at the five-leaf stage (Feekes 3 ).

Greenhouse experiments, 2018-19. Two CRD experiments (separated in time) in a three-way factorial of cultivar, inoculation level (6 clean autoclaved and dried wheat seeds and 10 infested seeds), and soil covering (covered and not covered), with 12 replications each, were performed to evaluate seedling stage resistance. The experiments were performed as described above for the adult plant experiments.

Disease evaluation. Evaluation of sharp eyespot in the field and adult-stage greenhouse experiments was conducted when all plants were fully headed (Feekes 10.5) (Large 1954). In all, 30 and 15 tillers were randomly collected from each subplot in the 2017-18 and 2018-19 field experiments, respectively. The evaluation was based 
on the area of stem and leaves covered by lesion on each tiller. Disease assessment of the adult plants was done using Chen's (2014) 0to-9 scale for adult plants (Supplementary Table S1). Disease assessment of the seedling-stage greenhouse experiment was conducted 45 days after inoculation according to Chen's (2014) 0-to-9 scale for wheat seedlings (Supplementary Table S2).

Data analyses. The data collected from each experiment were analyzed using R packages multcomp (Hothorn et al. 2016) and plyr (Wickham and Wickham 2016) on RStudio (version 0.98.1062). Although the data follow a multinomial distribution, we had 10 points along the scales for disease assessment and the data were approximately normal. Linear regression was used to build models from both field and greenhouse data. Tukey's range test was used to compare the disease severity among cultivars within each combination of inoculum level and soil-covering treatment.

\section{Results}

Preliminary field evaluations. Cultivar disease reactions under natural inoculation for two trials in growers' fields provided a baseline for evaluating the same cultivars under artificial inoculation in subsequent trials. Disease symptoms were severe in both trials, though somewhat more so in 2014 than 2015 (Table 1). Ranking of the cultivars was the same in the trials, with the cultivars Rosalyn and Bobtail being the most resistant. The earlymaturing cultivar LCS Art Deco was too far advanced in maturity to rate in 2015.

Artificially inoculated field experiments. Fields experiments quantified the effects of planting date, inoculation level, and cultivar on severity of sharp eyespot. Final analyses were conducted on individual experiments owing to frequent interactions between experiments and treatments.

For the 2017-18 field experiments, inoculum level, cultivar, and their interaction were significant for both the Botany Farm

Table 1. Tukey's range test of mean disease ratings of sharp eyespot for winter wheat cultivars under natural infestation in yield trials of 2014 and 2015 in Forest Grove, $\mathrm{OR}^{\mathrm{z}}$

\begin{tabular}{llc}
\hline Cultivar & $\mathbf{2 0 1 4}$ & $\mathbf{2 0 1 5}$ \\
\hline LCS Art Deco & $5.0 \mathrm{a}$ & $\ldots$ \\
LCS Biancor & $4.5 \mathrm{a}$ & $4.0 \mathrm{a}$ \\
Kaseberg & $4.3 \mathrm{ab}$ & $3.0 \mathrm{ab}$ \\
Ladd & $3.0 \mathrm{bc}$ & $2.5 \mathrm{bc}$ \\
Rosalyn & $2.0 \mathrm{~cd}$ & $1.8 \mathrm{~cd}$ \\
Bobtail & $1.5 \mathrm{~d}$ & $1.3 \mathrm{~d}$ \\
\hline
\end{tabular}

${ }^{\mathrm{z}}$ Means followed by same letter are not significantly different at an $\alpha$ level of 0.05 . Ratings use a 0 -to- 5 scale based on the combination of whitehead expression and stem discoloration, where $0=$ no disease and $5=$ severe disease.

Table 2. Tukey's range test of mean disease ratings of sharp eyespot for six winter wheat cultivars under four artificial inoculation levels in the 2017-18 field experiments at two locations (Botany Farm and Hyslop Farm $)^{\mathrm{z}}$

\begin{tabular}{|c|c|c|c|c|c|c|c|c|}
\hline \multirow[b]{2}{*}{ Cultivar } & \multicolumn{4}{|c|}{$\begin{array}{c}\text { Inoculum rate }(\mathrm{kg} / \mathrm{ha}) \text { - } \\
\text { Botany Farm }\end{array}$} & \multicolumn{4}{|c|}{$\begin{array}{c}\text { Inoculum rate }(\mathrm{kg} / \mathrm{ha}) \text { - } \\
\text { Hyslop Farm }\end{array}$} \\
\hline & $\mathbf{0}$ & 112 & 224 & 336 & $\mathbf{0}$ & 112 & 224 & 336 \\
\hline $\begin{array}{l}\text { LCS Art } \\
\text { Deco }\end{array}$ & $4.99 \mathrm{a}$ & $6.43 \mathrm{a}$ & $6.57 \mathrm{a}$ & $6.79 \mathrm{ab}$ & $0.07 \mathrm{a}$ & $2.25 \mathrm{a}$ & $2.29 \mathrm{a}$ & $2.75 \mathrm{a}$ \\
\hline $\begin{array}{l}\text { LCS } \\
\text { Biancor }\end{array}$ & $5.18 \mathrm{a}$ & $6.18 \mathrm{a}$ & $5.75 \mathrm{~b}$ & $6.17 \mathrm{~b}$ & $0.01 \mathrm{a}$ & $1.74 \mathrm{~b}$ & $2.17 \mathrm{a}$ & $2.04 \mathrm{~b}$ \\
\hline Kaseberg & $5.52 \mathrm{a}$ & $5.98 \mathrm{ab}$ & $6.44 \mathrm{a}$ & $6.83 \mathrm{a}$ & $0.03 \mathrm{a}$ & $0.95 \mathrm{c}$ & $1.33 \mathrm{~b}$ & $1.24 \mathrm{c}$ \\
\hline Ladd & $5.79 \mathrm{a}$ & $6.63 \mathrm{a}$ & $6.52 \mathrm{a}$ & $6.82 \mathrm{a}$ & $0.03 \mathrm{a}$ & $1.53 \mathrm{~b}$ & $2.20 \mathrm{a}$ & $1.93 \mathrm{~b}$ \\
\hline Rosalyn & $2.87 \mathrm{~b}$ & $4.63 \mathrm{c}$ & $2.93 \mathrm{~d}$ & $3.79 \mathrm{c}$ & $0.03 \mathrm{a}$ & $0.98 \mathrm{c}$ & $1.18 \mathrm{~b}$ & $1.22 \mathrm{c}$ \\
\hline Bobtail & $3.84 \mathrm{~b}$ & $4.90 \mathrm{bc}$ & $4.73 \mathrm{c}$ & $4.80 \mathrm{c}$ & $0.09 \mathrm{a}$ & $0.72 \mathrm{c}$ & $0.78 \mathrm{c}$ & $0.82 \mathrm{~d}$ \\
\hline
\end{tabular}

${ }^{\mathrm{z}}$ Means followed by the same letter are not significantly different at an $\alpha$ level of 0.05 . Ratings use the 0 -to- 9 scale of Chen (2014), where $0=$ no disease and $9=$ plant dead.
(September planting) and Hyslop Farm (October planting) (Supplementary Table S3). There was considerable sharp eyespot in the noninoculated plots at the Botany Farm but very little at Hyslop Farm (Table 2). At both locations, there was a larger change in sharp eyespot severity between the zero inoculation level and the other three inoculation levels than there were among the three nonzero inoculation levels. However, the number of statistical groupings increased with inoculum level at both sites. Bobtail and Rosalyn were usually rated as most resistant. However, Bobtail was more resistant than Rosalyn at the Botany Farm and vice versa at Hyslop Farm. Rankings among the more susceptible cultivars were less consistent.

For the 2018-19 field experiments, inoculum level, cultivar, and their interaction were significant for both the Botany Farm and Hyslop Farm experiments (Supplementary Table S4). At both sites, there were higher disease levels in the early-planted than in the later-planted experiment, and more disease in the inoculated than in the noninoculated plots (Table 3). However, the difference between noninoculated and inoculated plots within experiments was greater than between the early- and late-planted experiments. As in 2017-18, cultivars Bobtail and Rosalyn usually had the lowest disease scores, with other cultivars being more variable.

Greenhouse experiments. Greenhouse experiments of seedling and adult plants evaluated effects of inoculum level, soil covering of inoculum, and cultivar on severity of sharp eyespot. No infections were observed on the noninoculated control plants; therefore, the controls were not included in the analyses. Cultivar was significant for both adult- and seedling-stage experiments in both growing seasons. Covering inoculum with soil had nonsignificant effects on disease severity and was only statistically significant for the seedling-stage experiments. Inoculum level, which was only included in the 2017-18 experiments, was not significant for either the adult or the seedling

Table 3. Tukey's range test of mean disease ratings of sharp eyespot for six winter wheat cultivars inoculated or noninoculated at two planting dates (early and late) and two locations (Botany Farm and Hyslop Farm) in the 2018-19 winter wheat season ${ }^{z}$

\begin{tabular}{|c|c|c|c|c|c|c|c|c|}
\hline \multirow[b]{3}{*}{ Cultivar } & \multicolumn{4}{|c|}{$\begin{array}{c}\text { Inoculum rate (kg/ha) - } \\
\text { Botany Farm }\end{array}$} & \multicolumn{4}{|c|}{$\begin{array}{c}\text { Inoculum rate }(\mathrm{kg} / \mathrm{ha}) \text { - } \\
\text { Hyslop Farm }\end{array}$} \\
\hline & \multicolumn{2}{|c|}{$\begin{array}{c}\text { Early } \\
\text { Planting }\end{array}$} & \multicolumn{2}{|c|}{$\begin{array}{c}\text { Late } \\
\text { Planting }\end{array}$} & \multicolumn{2}{|c|}{$\begin{array}{c}\text { Early } \\
\text { Planting }\end{array}$} & \multicolumn{2}{|c|}{$\begin{array}{c}\text { Late } \\
\text { Planting }\end{array}$} \\
\hline & $\mathbf{0}$ & 336 & $\mathbf{0}$ & 336 & $\mathbf{0}$ & 336 & $\mathbf{0}$ & 336 \\
\hline LCS Art Deco & $0.73 \mathrm{a}$ & $4.36 \mathrm{a}$ & $0.51 \mathrm{a}$ & $3.05 \mathrm{a}$ & $0.29 \mathrm{a}$ & $4.80 \mathrm{a}$ & $0.53 \mathrm{a}$ & $2.90 \mathrm{a}$ \\
\hline LCS Biancor & $0.21 \mathrm{~b}$ & $2.75 \mathrm{~b}$ & $0.68 \mathrm{a}$ & $2.13 \mathrm{~b}$ & $0.23 \mathrm{a}$ & $1.80 \mathrm{c}$ & $0.30 \mathrm{ab}$ & $1.48 \mathrm{~b}$ \\
\hline Kaseberg & $0.23 \mathrm{~b}$ & $1.80 \mathrm{c}$ & $0.53 \mathrm{a}$ & $1.66 \mathrm{bc}$ & $0.18 \mathrm{a}$ & $1.78 \mathrm{c}$ & $0.32 \mathrm{ab}$ & $1.35 \mathrm{~b}$ \\
\hline Ladd & $0.40 \mathrm{ab}$ & $1.86 \mathrm{bc}$ & $0.74 \mathrm{a}$ & $2.10 \mathrm{~b}$ & $0.34 \mathrm{a}$ & $2.78 \mathrm{~b}$ & $0.26 \mathrm{ab}$ & $1.30 \mathrm{~b}$ \\
\hline Rosalyn & $0.13 \mathrm{~b}$ & $1.23 \mathrm{c}$ & $0.69 \mathrm{a}$ & $1.08 \mathrm{c}$ & $0.18 \mathrm{a}$ & $1.53 \mathrm{c}$ & $0.10 \mathrm{~b}$ & $0.83 \mathrm{bc}$ \\
\hline Bobtail & $0.30 \mathrm{ab}$ & $1.18 \mathrm{c}$ & $0.35 \mathrm{a}$ & $1.48 \mathrm{bc}$ & $0.15 \mathrm{a}$ & $1.63 \mathrm{c}$ & $0.15 \mathrm{ab}$ & $0.58 \mathrm{c}$ \\
\hline
\end{tabular}

${ }^{\mathrm{z}}$ Means followed by the same letter are not significantly different at an $\alpha$ level of 0.05. Ratings use the 0-to-9 scale of Chen (2014), where $0=$ no disease and $9=$ plant dead.

Table 4. Tukey's range test of mean disease ratings of sharp eyespot for six winter wheat cultivars when inoculum was either covered (Cov) or not covered (NC) with soil in 2017-18 and 2018-19 greenhouse experiments at two growth stages (adult and seedling) in the Oregon State University West Greenhouse Facility ${ }^{\mathrm{z}}$

\begin{tabular}{|c|c|c|c|c|c|c|c|c|}
\hline \multirow[b]{3}{*}{ Cultivar } & \multicolumn{4}{|c|}{ 2017-18 } & \multicolumn{4}{|c|}{ 2018-19 } \\
\hline & \multicolumn{2}{|c|}{ Adult stage } & \multicolumn{2}{|c|}{ Seedling stage } & \multicolumn{2}{|c|}{ Adult stage } & \multicolumn{2}{|c|}{ Seedling stage } \\
\hline & $\operatorname{Cov}$ & $\mathrm{NC}$ & $\operatorname{Cov}$ & $\mathrm{NC}$ & Cov & NC & Cov & $\mathrm{NC}$ \\
\hline Deco & $6.92 \mathrm{a}$ & $6.52 \mathrm{a}$ & 1.64 & 2.48 & $4.76 \mathrm{ab}$ & $5.20 \mathrm{ab}$ & $2.54 \mathrm{ab}$ & $2.33 \mathrm{ab}$ \\
\hline LCS Bi & $4.36 \mathrm{c}$ & $2.96 \mathrm{c}$ & 1.72 & $1.88 \mathrm{bc}$ & $4.44 \mathrm{ab}$ & $4.44 \mathrm{bc}$ & $2.13 \mathrm{~b}$ & $3.13 \mathrm{a}$ \\
\hline Kaseberg & $2.68 \mathrm{~d}$ & $4.20 \mathrm{~b}$ & $2.00 \mathrm{ab}$ & $1.68 \mathrm{c}$ & $4.00 \mathrm{bc}$ & $4.40 \mathrm{bc}$ & $2.13 \mathrm{~b}$ & $2.23 \mathrm{~b}$ \\
\hline Ladd & $5.64 \mathrm{~b}$ & $4.52 \mathrm{~b}$ & $2.48 \mathrm{a}$ & $2.60 \mathrm{ab}$ & $5.08 \mathrm{a}$ & $5.28 \mathrm{a}$ & $3.00 \mathrm{a}$ & $3.33 \mathrm{a}$ \\
\hline Rosalyn & $4.00 \mathrm{c}$ & $3.72 \mathrm{bc}$ & $2.04 \mathrm{ab}$ & $2.52 \mathrm{ab}$ & $4.16 \mathrm{~b}$ & $4.09 \mathrm{c}$ & $2.38 \mathrm{~b}$ & $2.66 \mathrm{ab}$ \\
\hline Bobtail & $2.68 \mathrm{~d}$ & $3.04 \mathrm{c}$ & $2.24 \mathrm{ab}$ & $2.84 \mathrm{a}$ & $3.44 \mathrm{c}$ & $3.92 \mathrm{c}$ & $2.40 \mathrm{~b}$ & $2.94 \mathrm{a}$ \\
\hline
\end{tabular}

${ }^{\mathrm{z}}$ Means followed by same letter are not significantly different at an $\alpha$ level of 0.05 . Ratings use the 0 -to- 9 scale of Chen (2014), where $0=$ no disease and $9=$ plant dead 
growth stage. The interaction between cultivar and soil covering was highly significant in the 2017-18 adult-stage experiment and at $P=$ 0.07 in the 2018-19 seedling-stage experiments (Supplementary Table S5). Mean disease severity of the adult stage was greater than that of the seedling stage (Table 4).

For the adult-stage experiments of both growth seasons, LCS Art Deco and Ladd were the most susceptible cultivars. However, LCS Art Deco was more susceptible than Ladd in the 2017-18 season, and vice versa in the 2018-19 season. Bobtail and Rosalyn were the most resistant cultivars, with Bobtail being numerically but not statistically more resistant than Rosalyn. Rankings of the other two cultivars were not consistent (Table 4).

Compared with adult-stage experiments, the seedling-stage experiments had less statistical separation. Ladd was rated as the most susceptible cultivar but the ranking of other cultivars was not consistent between seasons (Table 4).

\section{Discussion}

For sharp eyespot, two variety trials conducted with natural inoculation in the Willamette Valley provided sufficient disease pressure for consistent ranking of cultivars (Table 1). However, similar trials conducted in other years or locations did not show the same result (unpublished data). Similarly, only one of our four field screening experiments provided sufficient disease pressure to differentiate resistance among cultivars in the absence of artificial inoculation (Tables 2 and 3). All four experiments were conducted in fields that had been fallow for 1 year prior but cropped to winter wheat trials 2 years prior. We have no explanation for the variation of disease expression among these different trials.

Initial observations in variety trials (Table 1) and commercial winter wheat fields of the Willamette Valley (unpublished data) have shown cultivars Bobtail and Rosalyn to be considerably more resistant than other cultivars, with Bobtail being somewhat more resistant than Rosalyn. In our field inoculation trials (Table 2 and 3), these two cultivars consistently showed the lowest disease severities at the highest rate of artificial inoculation, though they were not always significantly different from some of the more susceptible cultivars and the ranking of them fluctuated. This result is consistent with previous reports. In New Zealand, cultivars varied from highly resistant to highly susceptible, and intermediate cultivars sometimes fluctuated in ranking among trials (Cromey et al. 2005, 2012). Wheat cultivars in China also varied greatly in degree of susceptibility, with cultivars sometimes varying in rank depending on location of the trial (Li et al. 2013).

In 2017-18, the early-planted plots at Botany Farm had much higher levels of sharp eyespot compared with the later-planted trial at Hyslop Farm. However, it is impossible to know whether this was an effect of planting date or an aspect of the particular field in which the trial was planted. We evaluated early- and late-seeded trials at both locations in 2018-19. In that season, artificial inoculation was crucial to achieving adequate disease levels for effective screening but planting date had very little impact. This result may not necessarily hold true in all years, however, because early planting has often been noted to increase the severity of sharp eyespot (Cromey et al. 2012) (unpublished data).

Effective screening for disease resistance usually requires high and spatially uniform disease pressure and consistency of results among years. Field trials are often unable to provide these characteristics without augmentation of inoculum. Greenhouse evaluation is often desired, because a controlled environment allows for use of less plant material (especially important in early generations of breeding) and, in some cases, may allow for multiple rounds of evaluation per year through either multiple trials in the greenhouse or a combination of greenhouse and field trials. Results of greenhouse trials do not always correlate with field ratings. Furthermore, evaluation of seedlings, which is fast and may allow multiple cycles per year, may not correlate with evaluations of plants tested in the adult stage. Evaluation of adult plants may be more realistic but requires more time. For winter cereals, evaluating adult plants in the greenhouse is especially complicated because of their vernalization requirement.
Greenhouse inoculations were much less successful in categorizing resistance to sharp eyespot. The seedling inoculations were inadequate as a screening method because disease severity was very low and the more resistant cultivars (Bobtail and Rosalyn) showed little difference from the susceptible cultivars (Table 4). Disease severity was considerably higher in the adult plant greenhouse trials but they were still very inconsistent in distinguishing resistant from susceptible cultivars. Neither altering the inoculation rate nor covering the inoculum with soil to help maintain moisture levels had any substantial impact on disease ratings in the greenhouse studies (Supplementary Tables S4 and S5). In New Zealand, greenhouse ratings of adult plants were also often inconsistent with results from field trials (Cromey et al. 2012).

Infection by $R$. cerealis occurs through penetration of plant tissue by the hypha (Cromey et al. 2012). Therefore, shorter distances between inoculum and plants increased the probability of infection (Colbach et al. 1997). Close contact with inoculum is relatively easy to attain in greenhouse studies. In our field trials, inoculum was scattered by hand as close to the wheat plants as possible. This method might not be practical if larger numbers of plots are to be evaluated in a breeding program. However, we have more recently modified a homeowner's drop spreader (Scott Turf Builder Classic Drop Spreader; Scotts Miracle-Gro Company, Marysville, OH, U.S.A.) to place inoculum directly over the wheat rows only, and not between rows. Using this piece of equipment, we were easily able to inoculate 1,600 field plots in approximately $6 \mathrm{~h}$.

Artificial inoculation of six Pacific Northwest wheat cultivars with $R$. cerealis was conducted in both the field and greenhouse. Although complete resistance was not observed, some cultivars such as Bobtail and Rosalyn with low disease severity have been identified. These cultivars can be grown in areas where sharp eyespot is a known problem, and they are also being used as parental materials in the Oregon State University Wheat Breeding and Genetics Program. Growing highly susceptible cultivars such as LCS Art Deco in areas where sharp eyespot has caused losses in the past would be very risky. Artificial inoculation in the field can be utilized as an effective method to distinguish the most resistant from the most susceptible wheat genotypes. Results were inconsistent in the greenhouse for both adult stage and seedling stages. Therefore, artificial inoculation in the field is a recommended method for selecting resistance to wheat sharp eyespot.

\section{Acknowledgments}

We thank P. M. Hayes for making laboratory facilities available, Y. Jiang for help in data analyses, and M. J. Larson for providing genetic materials.

\section{Literature Cited}

Bockus, W. W., Bowden, R. L., Hunger, R. M., Murray, T. D., and Smiley, R. W., eds. 2010. Compendium of Wheat Diseases and Pests, 3rd ed. American Phytopathological Society, St. Paul, MN, U.S.A.

Chen, J. 2014. Analysis of QTL conferring resistance to sharp eyespot (Rhizoctonia cerealis) in wheat. Ph.D. dissertation, China Agricultural University, Beijing, China.

Chen, J.-H., Zhang, C.-C., Xu, D.-F., and Zhu, S.-Y. 2011. Research progress of wheat sharp eyespot. Mod. Agric. Sci. Technol. 1.

Clarkson, J. D. S., and Cook, R. J. 1983. Effect of sharp eyespot (Rhizoctonia cerealis) on yield loss in winter wheat. Plant Pathol. 32:421-428.

Colbach, N., Lucas, P., Cavelier, N., and Cavelier, A. 1997. Influence of cropping system on sharp eyespot in winter wheat. Crop Prot. 16:415-422.

Cromey, M. G., Butler, R. C., Boddington, H. J., and Moorhead, A. R. 2002 Effects of sharp eyespot on yield of wheat (Triticum aestivum) in New Zealand. N. Z. J. Crop Hortic. Sci. 30:9-17.

Cromey, M. G., Butler, R. C., Munro, C. A., and Shorter, S. C. 2005. Susceptibility of New Zealand wheat cultivars to sharp eyespot. N. Z. Plant Prot. 58:268-272.

Cromey, M. G., Hide, C. C. L., and Meenken, E. D. 2012. Resistance to sharp eyespot in wheat. N. Z. Plant Prot. 65:204-212.

Hamada, M. S., Yin, Y., Chen, H., and Ma, Z. 2011. The escalating threat of Rhizoctonia cerealis, the causal agent of sharp eyespot in wheat. Pest Manage. Sci. 67:1411-1419.

Hammouda, A. M. 2003. First report of sharp eyespot of wheat in Egypt. Plant Dis 87:598.

Hothorn, T., Bretz, F., Westfall, P., Heiberger, R. M., Schuetzenmeister, A., Scheibe, S., and Hothorn, M. T. 2016. multcomp: Simultaneous inference in general parametric models. https://cran.r-project.org/web/packages/multcomp/ index.html 
Large, E. C. 1954. Growth stages in cereals illustration of the Feekes scale. Plant Pathol. 3:128-129.

Lemańczyk, G. 2010. Occurrence of sharp eyespot in spring cereals grown in some regions of Poland. J. Plant Prot. Res. 50:505-512.

Li, H., Wang, X., Chen, H., Li, W., Liu, D., and Zhang, H. 2013. Reaction of wheat-Thinopyrum progenies and wheat germplasm to sharp eyespot. Acta Agron. Sin. 39:999-1012.

Li, W., Guo, Y., Zhang, A., and Chen, H. 2017. Genetic structure of populations of the wheat sharp eyespot pathogen Rhizoctonia cerealis anastomosis group D subgroup I in China. Phytopathology 107:224-230.
Lipps, P. E., and Herr, L. J. 1982. Etiology of Rhizoctonia cerealis in sharp eyespot of wheat. Phytopathology 72:1574-1577.

Liu, J., and Mundt, C. C. 2020. Genetic structure and population diversity in the wheat sharp eyespot pathogen Rhizoctonia cerealis in the Willamette Valley, Oregon, USA. Plant Pathol. 69:101-111.

Lovell, D. J., Parker, S. R., Baldwin, S., and Fraaije, B. A. 2003. Peduncle rot of dwarf wheat caused by Rhizoctonia cerealis. Plant Health Prog. 4. https:// apsjournals.apsnet.org/doi/10.1094/PHP-2003-0717-01-HN

Wickham, H., and Wickham, M. H. 2016. plyr: Tools for splitting, applying and combining data. https://cran.r-project.org/web/packages/plyr/index.html 